\title{
The Impact of Trust on the Development of Structural and Social Bonds in B2B Companies
}

\author{
Irene Samanta \\ Department of Business Administration, University of West Attica, Athens, Greece \\ Email address: \\ isamanta@uniwa.gr \\ To cite this article: \\ Irene Samanta. The Impact of Trust on the Development of Structural and Social Bonds in B2B Companies. American Journal of Theoretical \\ and Applied Business. Vol. 7, No. 2, 2021, pp. 30-38. doi: 10.11648/j.ajtab.20210702.11
}

Received: April 3, 2021; Accepted: April 19, 2021; Published: June 4, 2021

\begin{abstract}
The present research examines the impact of trust, social and structural bonds, in a B2B relationship between companies in times of economic crisis. The aim of the research is to investigate the importance of trust, social and structural bonds in the creation and maintenance of long-term relationships in B2B firms. A quantitative research was carried out using a structured questionnaire, distributed by e-mail. Forty-four (44) medium and large companies, responded, based in Attica Greece, were sampled for the survey. According to the findings, companies have incorporated relational marketing into their philosophy. All of the participated companies maintain long-term partnerships with other companies in the sector. All the companies that took part in the survey have become aware of the important role that trust plays in their collaborations, as well as the role of structural bonds, while the results give less weight to social bonds. Companies choose long-term relationships, and the present research highlights the important role of a good partnership. Therefore, in order to survive, manufacturers develop cooperative relationships with each other in order to jointly face the challenges of the times. Project partnerships, consortia, associations of companies and joint partnerships are now being created in order to take part in public procurement or to undertake the execution of a project.
\end{abstract}

Keywords: Relational Marketing, Trust Development, B2B Firms, Sructural Bonds, Social Bonds

\section{Introduction}

The science of relational marketing, refers to the creation and maintenance of business to business relations and consists the growing tendency to cultivate close contact with the customer base in order for a company to gain and maintain a competitive advantage.

The theoretical background of this research lies in the agency theory, dealing with the resolution of problems that may arise between principals (such as shareholders) and their representatives, as well as in the theory of resource dependency theory. These two theories explain the need to establish long-term cooperative relationships. In such a relationship each of the company involved has different interests and their actions tend to diverge (agency theory) Ashnai et al.,[1]. This divergence of interests can be reduced by creating appropriate incentives for the agent and at the same time designing a monitoring system to reduce his opportunistic behavior. In addition, it could compensate the originator if it acts against him or be charged with loss of resources in case of wrong decisions (bonding cost). The resource dependency theory recognizes that organizations depend on resources derived from an organization's environment and form a basis of power. Power and dependence on resources are directly linked as the power that Organization A has over B is equal to the dependence that Organism B has on the resources of Organization A Barry \& Doney, [4]. Through their cooperation they secure the necessary resources and gain an ally, which until then may have been a strong competitor Samanta [20]. In the literature we encounter three concepts for the development of sustainable and functional long-term cooperation relationships in a market: trust, social bonds and structural bonds where their appearance or absence identifies different types of relationships.

The importance attached to trust in business to business relations has been demonstrated by a wide range of empirical studies Cannon et al., [2] and according to Le et al., [11] 'mutual trust is by far the most important factor characterizing a successful relationship'. In particular, where 
there is a high degree of uncertainty and a lack of information about a new partner Barry \& Doney, [4], research has shown that the need for trust is increased. Roy et al., [18] concluded that through the creation and maintenance of long-term cooperative relationships, customer satisfaction and loyalty increases, while reducing service costs (in operational, administrative and service terms) as long as the processes are standardized, thanks to previous knowledge and experience. However, before trust is being developed, there must be a safety net and some engagement techniques developed that will reduce the uncertainty of the results of cooperation, building a relationship that will benefit both cooperating parties. In the literature there are two major categories of bonds, social and structural bonds. These two broad categories, mentioned by Barry \& Doney, [4], also include a wide variety of sub-categories of bonds, such as technical bonds, geographical bonds, time ties, knowledge bonds, psychological and ideological bonds Lee et al., [4].

The aim of the research is to investigate the importance of trust, social and structural bonds in the creation and maintenance of long-term relationships in enterprises in the construction industry. In recent years construction companies have faced a series of adverse economic events. Financial Reports point out the reduced results for eleven consecutive quarters, especially in the last six quarters where declines have been increasing rapidly. In order to survive, manufacturers develop cooperative relationships with each other in order to jointly face the challenges of the times. Project partnerships, consortia, associations of companies and joint partnerships are now being created in order to take part in public procurement or to undertake the execution of a project.

\section{Literature Review}

\subsection{Relational Marketing}

Relational Marketing is the process of finding, concluding, maintaining, strengthening or even terminating, whenever this is necessary, relationships with customers and other important agents in the relationship, so that the objectives of all stakeholders are achieved through mutual exchange and fulfilment of promises Paulssen [16]. Establishing relationships between $\mathrm{B} 2 \mathrm{~B}$ companies takes time and contains a number of stages until its creation. The creation of a cooperative relationship does not imply its eternal existence, because the non-satisfaction of one member can bring about its termination. What creates trust between the parties involved is the mutual exchange and keeping of promises. The main feature of successful relationships is cooperation between actors, which includes day-to-day work and crisis management. Relational marketing is a philosophy of the company, which places its relationships at the heart of its operation. Samanta \& Danson [19] consider that the creation and maintenance of long-term relationships leads to an increase in customer loyalty and satisfaction, while also reducing service costs due to the standardization of transactions and the knowledge and experience gained during the transaction with the same customer.

In addition, the friendly relationship created with the customer and the exchange of information gives the company a competitive advantage through the development of strong bonds with the customer. These bonds may prove beneficial to both parties involved, particularly if both aim to achieve long-term benefits Lai et al., [10]. According to Roy et al., [18], through the development of long-term cooperative relationships, resource and time savings are achieved through the automation of the processes. Transaction formalities are reduced and at the same time, resources and necessary technology are ensured for partners.

In the literature we encounter three concepts for the development of sustainable and functional long-term cooperation relationships in a market: trust, social bonds and structural bonds where their appearance or absence identifies different types of relationships.

\subsection{The Concept and Levels of Trust in B2B Companies}

The role of trust in business to business relations has been demonstrated by empirical studies Zenger [31]. This belief reduces the need for legal structures and guarantees and thus leads to a reduction in transaction costs Kumar et al., [9]. Moreover, it is impossible to create legal agreements covering any possibility, especially in long-term partnerships Ashnai et al.,[1]. In these types of collaborations there is always the risk of the manifestation of opportunist behaviour of the cooperating parties. However, if the relationship is based on mutual trust and the parties involved consider that unexpected events will be dealt with in a way that benefits both sides, then this risk is minimized. This behavior further favors the long-term orientation of cooperation relations between enterprises, reduces the perceived risk that may a Graça \& Barry [6] rise from new investments in an existing cooperative relationship Shou et al., [24] and lead to the extension and strengthening of this cooperation. Therefore a large part of international academic community argues that trust reduces uncertainty in business-to-business partnerships and increases a sense of safety Zenger [31], while at the same time leads to higher levels of fidelity and dedication to a relationship.

Creating and developing trust leads to efficiency and productivity and leads to successful partnerships Ashnai et al., [1]. Relationships that are characterized by a high degree of trust lead to commitment, as they are highly valued by the parties involved because commitment Paulssen [16]. Makes a company vulnerable, and therefore the search for a trusted partner is required. According to Román \& Lacobucci [17] the levels of trust we encounter in business relationships relate to Contractual Trust and reflect the expectation of the parties involved, that their partner will fulfill his contractual obligations as they arise from written or unwritten agreements between them. At a higher level we find the Confidence of Competencies, which is characterized by mutual trust of the parties that there will be proper execution of tasks, with reliability and consistency. In Good Faith trust 
the involved parties demand from their partner not only to fulfill the contractual obligations, but also to take any other action that could lead the relationship even higher. Voss et al., [28] formulated the Generalized Trust which is promoted by common rules of behavior and social mechanisms and increases the willingness to cooperate. The Trust System which is based on written rules whose application is controlled by institutional organizations. Trust in Processes which is being developed through the repetition of processes between two parties and is directly related to their behavior. Confidence in a Personality which depends on the personal characteristics of individuals and concerns their willingness to trust their partner. This type of trust is extremely important in the early stages of a relationship, when there is not yet, enough practical knowledge to evaluate the partner. Trust is a process that is constantly changing during a collaboration, can take many forms and can be enhanced with appropriate marketing strategies.

\subsection{Trust Development}

Cater \& Cater [3] state that variables that enhance the development of trust. They argue that the more dynamic the environment, the greater the need to develop trust to reduce levels of uncertainty. The greater the investments in people, equipment and processes, in the context of a partnership the greater the dependence on the specific partner, and therefore the greater need to develop trust. Cannon et al., [2] report that the more frequent contacts are made within a partnership, the lower the transaction costs and the greater the opportunities for evaluation, favoring the development of trust. According to $\mathrm{Wu}$ et al., [30], the partner's reputation, experience and satisfaction from previous collaborations as well as his perceptions of the special investments related to the relationship are factors that develop trust. Voss et al., [28] focus on the characteristics of the people involved in the relationship, arguing that the greater the experience of individuals, the greater the trust in them by their partners. Additional factors are confidentiality, integrity, discretion and the general orientation towards the relationship, which stems from the corporate culture and organizational structure of each company. At the same time, they introduced another variable, the perceived importance and formality of cooperation, arguing that the greater the importance, the greater the need for trust, while the greater the formality, the less the need for trust. But when it comes to business to business relationships, we have to keep in mind that building trust is a two-way process and requires mutual concessions from stakeholders.

H1: The existence of trust in a partnership brings financial benefits to the business

\subsection{The Concept of Structural and Social Bonds and Their Relationship with Trust}

In order to build trust, there must be a safety net and the development of some engagement techniques that will reduce the uncertainty of the outcome of the partnership, building a relationship that will benefit both partners. Cater \& Cater [3] distinguish two bonds categories, the structural and social bonds that include a wide variety of subcategories, such as technical bonds, geographical bonds, time bonds, knowledge bonds, psychological and ideological bonds.

Dwyer et al., [5] point out the usefulness of bonds as a tool for determining the strength of the relationship between trading parties. It is a combination of regulatory and financial commitments, which helps to address any divisive trends and at the same time strengthens the relationship as a long-term strategic importance. The lack of these bonds can be considered as an indication of temporary and vulnerable cooperation. Bonds can act as a deterrent to ending a relationship, because they create barriers to escape. Social bonds are defined as the close interpersonal relationships that develop between customers and suppliers $\mathrm{Wu}$ et al., [30]. Ideally, a relationship is characterized by social bonds that include feelings of friendship, acceptance, mutual respect, and sympathy. According to Wilson (1995), social bonds enhance information exchange and business to business communication, leading the relationship to higher levels.

Terawatanavong \& Quazi, [27] describe social bonds as dynamic processes that can positively affect both parties to a partnership and they can pre-exist an cooperation. However, they develop gradually as people from the partner companies come into contact and get to know each other better. On the other hand, just because they relate to people, social bonds can be weakened when people who have built relationships are removed from their jobs.

Paulssen [16] classified social bonds into Cultural that favor multicultural negotiations referring to language, nationality and religion. These are elements that are not going to change and which contribute to the strengthening of a relationship, in those cases where mutual efforts are made to understand these diversities. Japanese are the classic example, as they invest generously in time and money in order to meet their future partners. Psychological bonds concern the perceptions that have been established by each company, these are purely personal preferences that can nevertheless affect a collaboration. Ideological bonds that are divided into stable and dynamic. The bonds that do not change in intensity over time are stable, for example the desire to work with another company due to its nationality. On the contrary, dynamic bonds are constantly evolving and influenced by new trends, for example the common demand for respect and protection of the environment. These bonds exist as long as the partnership exists.

Social bonds can be also external and concern the indirect contact of partners through groups and organizations that are points of reference and influence for themselves, such as friends, family, the various organizations and communities to which they belong Graça \& Barry [6] and this category of bonds enhances the maintenance of the relationship [ ]. In order social bonds to be effective in a partnership, they do not have to pre-exist, but they can be created through the business relationship and strengthened over time.

H2: The existence of social bonds brings financial benefits 


\section{to the business}

Relationships governed by structural bonds are more difficult to end, because termination would mean high costs for the parties involved and difficulty in finding new partners Román \& Iacobacci [17], In a business agreement, the parties are bound by the tangible, financial and strategic benefits contained in that agreement. These benefits underlie the structural bonds that develop in the early stages of a relationship to reduce the risk of non-reciprocal behavior Mital et al., [15]. In structured partnerships, Ha et al., [8] treat them as an obstacle to exiting the partnership and see them as evidence of commitment to the relationship. It is observed that the better the alternatives on the market, the weaker the structural bonds.

MacKenzie et al., [14] distinguish the structural bonds in Customization of products and production processes in order to meet customer needs. That is, the changes that can be made in the products of the company in order to meet the customer needs (product customization) or improve the services provided by the product, the Financial transactions referring to a policy of lower prices to some important customers and the Exchange of Information, which enhances the participation in decision making process and increases commitment to the relationship.

Mital et al., [15] classifies structural bonds into Economic ones such as lower prices or favorable payment terms. These bonds are considered unstable because they are affected by variables in the wider economic environment. The Technicians, who concern the production process and the product. They are developed in the first steps of a collaboration, the timelines of which are gradually developed as the continuous communication requires modern information systems that are adapted to each collaboration relationship. These systems usually result from long-term relationships and lead to reduced operating costs. Knowledge Bonds, which are developed before the partnership even starts and relate to the information that one company collects about another, such as what it can offer or what procedures it follows, and Geographical Bonds, which relate to the geographical proximity of the partner companies. Their power is greatly influenced by the business sector and can change over in the context of a partnership, as technology helps develop systems that reduce distances.

H3: The development of structural bonds brings financial benefits to the business

According to the above, social bonds represent the interpersonal characteristics of the cooperative relationship, while structural bonds represent the business to business, which are independent of interpersonal relationships Paulssen [16]. However, most relationships contain elements from both categories. These two types of bonds interact with each other Samaha et al., [21].

According to Román \& Lacobucci [17], structural bonds may be a necessity, but they are not a sufficient condition for maintaining the relationship. On the contrary, structural bonds are the most important for the relationship because they consolidate it and maintain its viability $\mathrm{Ha}$ et al., [8].
This approach is justified by the fact that in the bonding process, structural bonds dominate as relationships develop due to technological compatibility, economic advantages and other future opportunities, and so decision-making is more influenced by structural bonds than by social Styles et al., [25], who also argue that structural bonds are stronger than social ones and are necessary to maintain profitable customers. Social bonds acquire the importance of structural only when they can incorporate activities that will provide useful information about the market and the general context in which a partnership takes place.

The existence of structural bonds keeps both parties committed to a partnership, and they end up trusting each other as the relationship matures. On the contrary, it is extremely difficult for a company to justify low performance and maintain a relationship only because of the social bonds that have developed with another $\mathrm{Li}$ [12]. In every relationship there is a mixture of elements from both social and structural bonds, which positively affect the development of trust. Graça et al., [7] report that structural bonds strengthen social bonds, and then both together contribute to the development of trust. It is argued that trust reduces uncertainty and the degree of exposure and that it is necessary for the two parties to be able to commit psychologically or emotionally through expectations for future transactions and structurally through special investments Ha et al., [8].

\subsection{Research Methodology}

For the present research a quantitative research was conducted. A structured questionnaire was used to collect the quantitative data, based on previous studies and scales applied by Luthardt [13], Wilson [29], Sin et al. [23], and incorporated additional suggestions based on a review of the relevant literature on the benefits to the business from adopting relational marketing strategies and the cost of ending a relationship. After adapting the questions to the needs of the research, we concluded to a questionnaire consisted of a total of forty (40) closed-ended and multiplechoice questions for the most part, which are divided into two (2) sub-thematic sections.

A five-point Likert scale was used where 1 indicates Strongly disagree and 5 strongly agree.

Subsection 1: Contains questions regarding the adoption and implementation of relational marketing strategies.

Subsection 2: Relates to the financial benefits that result for the company and its operation, from the specific relationship. Includes a total of six (6) items.

Subsection 3: Based on the scale applied by Luthardt [13], on the measurement of the "trust" factor.

Subsection 4: Investigates the main features of the relationship of the participated companies, with specific reference partner, in terms of the concept of "social bonds". The scale used is based on research by Wilson [29]

Subsection 5: Investigates the main features of the relationship of the participated companies, with specific reference partner, in terms of the concept of "structural 
bonds". The scale of Sin et al. was the basis for the investigation of the factor "structural bonds" Sin et al., [23]

For the needs of the present research, construction companies in Greece were defined as the statistical population. The collection of quantitative data took place in 2018. Senior executives were asked to answer the questionnaire, who are considered to have the necessary knowledge and experience to provide the required information. The research sample is a sample of convenience - non-probability. The questionnaire was distributed via physical mail (courier) and via email to business executives in the context of construction industry. Of the total one hundred and thirty (130) questionnaires were distributed during April 2018, forty-four (44) fully completed forms were collected recording a response rate of $48.8 \%$.

As observed in the survey, mainly large and medium-sized companies responded, which together constitute $81.82 \%$ of the sample.

Regarding the turnover of companies in the year (2017), $2.27 \%$ answered that their turnover was less than two (2) million euros. $45.45 \%$ recorded a turnover between ten (10) and fifty (50) million euros, while more than half had a turnover of over fifty (50) million euros.

Almost one (1) in two (2) companies employs up to fifty (50) employees. $36.36 \%$ of them employ from fifty (50) to two hundred and fifty (250) people (medium enterprises), while only $15.91 \%$ of the companies that responded to the survey, have permanent staff exceeding two hundred and fifty

\section{(250) people.}

Regarding the years of operation $22.73 \%$ of the participated companies are in the construction industry less than ten (10) years, $38.64 \%$ have experience from ten (10) to twenty (20) years and $38.63 \%$ of the sample are companies that have been active in the construction industry for over twenty (20) years.

More than half of the companies (65.91\%) that participated in the survey stated that they have developed a long-term relationship with their partner. In particular, $40.91 \%$ have a relationship from five (5) to ten (10) years, while $25.00 \%$ have a relationship with their most important partner over ten (10) years.

The questionnaire is characterized by high reliability, as the correlation coefficient of Cronbach Alpha is equal to $0.922>0.70$.

In order to investigate and ensure structural validity, through the application of the Cronbach's Alpha coefficient, it appears that the specific scale of evaluation of the degree of implementation of relational marketing policies by companies, is reliable as the items of the scale records a high coefficient of internal coherence $0,811>0,70$.

\section{Research Results}

It is examined to what extent companies apply elements of relational marketing to their strategy (Table 1).

Table 1. Integration of relational marketing in organizational culture ( $1=$ Strongly Disagree, $5=$ Strongly Agree).

\begin{tabular}{|c|c|c|c|c|c|}
\hline & $\mathbf{N}$ & Minimum & Maximum & Mean & Standard Deviation \\
\hline $\begin{array}{l}\text { During our operation we have developed cooperative relationships that have } \\
\text { lasted over time }\end{array}$ & 44 & 1 & 5 & 4,36 & 0,685 \\
\hline $\begin{array}{l}\text { It is important for our company to have partners that we have known for a long } \\
\text { time }\end{array}$ & 44 & 1 & 5 & 4,43 & 0,625 \\
\hline We have invested a lot of time in order to build our relationship with the partner & 44 & 1 & 5 & 4,27 & 1,086 \\
\hline Our partnership will last as long as we are satisfied with it & 44 & 1 & 5 & 3,32 & 1,050 \\
\hline The exchange of promises is important for our cooperation & 44 & 1 & 5 & 4,20 & 0,954 \\
\hline Successful processing of several cases strengthens our cooperation & 44 & 1 & 5 & 4,73 & 0,357 \\
\hline Effective crisis management has a positive effect on our partnership & 44 & 1 & 5 & 4,67 & 0,408 \\
\hline
\end{tabular}

Relational marketing consists part of the corporate culture. The items related to the integration of business to business development policies, the degree of acceptance is over 4 and shows that the concept of relational marketing is established in the culture of companies.

Below it is explored to what extent companies are affected in their operation by integrating elements of relational marketing into their strategy (Table 2).

Table 2. Operational benefits derived from the integration of relational marketing in its organizational culture ( $1=$ Strongly Disagree, $5=$ Strongly Agree).

\begin{tabular}{|c|c|c|c|c|c|}
\hline & $\mathbf{N}$ & Minimum & Maximum & Mean & Std Deviation \\
\hline Long-term partnerships reduce service costs & 44 & 1 & 5 & 4,11 & 1,017 \\
\hline Standardization of transactions reduces the cost of service & 44 & 1 & 5 & 4,41 & 0,658 \\
\hline Partners' knowledge reduces service cost & 44 & 1 & 5 & 4,36 & 0,650 \\
\hline The experience of trading with the same partner reduces the cost of service & 44 & 1 & 5 & 4,39 & 0,655 \\
\hline Through long-term cooperation we achieve resource savings & 44 & 1 & 5 & 4,30 & 0,734 \\
\hline $\begin{array}{l}\text { Through long-term cooperation we ensure the necessary technology for our } \\
\text { modernization }\end{array}$ & 44 & 1 & 5 & 3,84 & 0,608 \\
\hline
\end{tabular}

Factor analysis resulted in a new variable with average value presented in the last line of the above table.

The new variable Benefits_1: Financial, shows an average value of 4.35 , which means that companies estimate that the financial benefits they gain through relational marketing are very important for their operation. 
The above shows that the implementation of relational marketing has a large positive effect on the financial reports of construction companies.

According to the research hypotheses given in the theoretical part, the relationship between the three factors of relational marketing (trust, social and structural bonds) and the benefits derived for the company as a result of its relationships with its partners is examined.

Before investigating the validity of the research hypotheses, the basic descriptive measures of all the individual factors of the factors "trust", "social bonds" and "structural bonds" are presented (Tables 3, 4 and 5).

Table 3. Trust within business to business relationships (1=Strongly Disagree, 5) Strongly Agree.

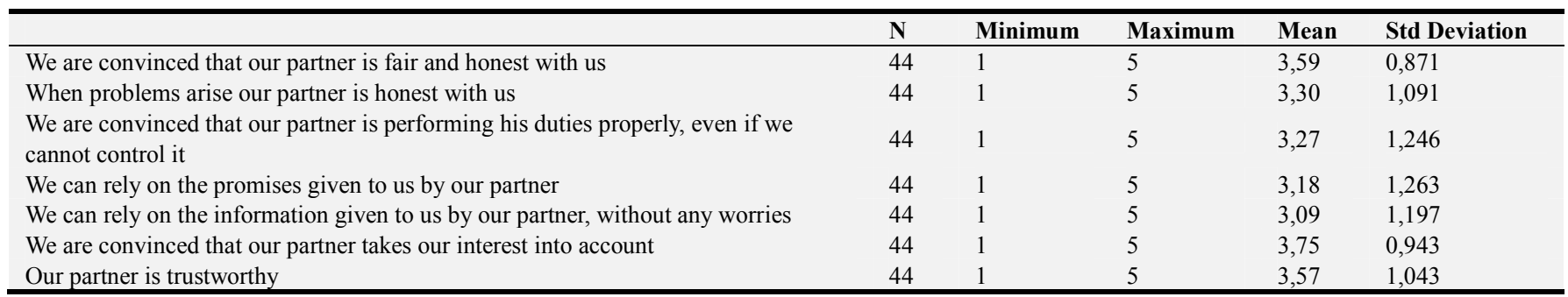

According to the results of Table 3, the degree of acceptance of all sub-questions of the "trust" factor is above the average of the scale $(2.50)$.

Table 4. Social bonds as relational marketing factor ( $1=$ Strongly Disagree, $5=$ Strongly Agree)

\begin{tabular}{|c|c|c|c|c|c|}
\hline & $\mathbf{N}$ & Minimum & Maximum & Mean & Std Deviation \\
\hline $\begin{array}{l}\text { The development of friendly relationships between the employees of our companies } \\
\text { is an important reason for maintaining our cooperation }\end{array}$ & 44 & 1 & 5 & 2,07 & 1,065 \\
\hline The people of our company and our partner, agree on an interpersonal level & 44 & 1 & 5 & 3,02 & 1,151 \\
\hline $\begin{array}{l}\text { The personality of the executives of our company matches the personality of the } \\
\text { executives of our partner }\end{array}$ & 44 & 1 & 5 & 2,98 & 1,089 \\
\hline Our partner understands the spirit of our company & 44 & 1 & 5 & 3,68 & 0,674 \\
\hline $\begin{array}{l}\text { The relationship between the people of our company and the people of our partner, is } \\
\text { personal }\end{array}$ & 44 & 1 & 5 & 2,57 & 0,925 \\
\hline Social: Social bonds & 44 & 1 & 5 & 2,94 & 0,728 \\
\hline
\end{tabular}

Table 5. Structural bonds as relational marketing factor ( $1=$ Strongly Disagree, $5=$ Strongly Agree).

\begin{tabular}{|c|c|c|c|c|c|}
\hline & $\mathbf{N}$ & Mininum & Maximum & Mean & Std Deviation \\
\hline Our partner has acquired knowledge and expertise around our special needs & 44 & 1 & 5 & 4,09 & 0,563 \\
\hline To build the relationship with our partner we have made a large investment in money & 44 & 1 & 5 & 3,18 & 0,896 \\
\hline To build the relationship with our partner we have made a great investment in effort & 44 & 1 & 5 & 3,95 & 0,429 \\
\hline $\begin{array}{l}\text { In order to build a similar relationship with another partner, we need to make large } \\
\text { investments in time, money and effort. }\end{array}$ & 44 & 1 & 5 & 4,48 & 0,664 \\
\hline We feel dependent on our partner & 44 & 1 & 5 & 3,43 & 0,846 \\
\hline
\end{tabular}

Table 6. Correlations between: Financial Benefits and "Trust" - "Social bonds" - "Structural bonds".

\begin{tabular}{|c|c|c|c|c|c|}
\hline & & Benefits_1: Financial & Reliance: Trust & Social: Social bonds & Structural: Structural bonds \\
\hline \multirow{3}{*}{$\begin{array}{l}\text { Benefits_1: } \\
\text { Financial }\end{array}$} & Pearson Correlation & 1 &, $434^{* *}$ &,- 042 & 295 \\
\hline & Sig. (2-tailed) & &, 003 &, 786 &, 050 \\
\hline & $\mathrm{N}$ & 44 & 44 & 44 & 44 \\
\hline \multirow[t]{2}{*}{ Reliance: Trust } & Sig. (2-tailed) &, 003 & &, 002 & ,387 \\
\hline & $\mathrm{N}$ & 44 & 44 & 44 & 44 \\
\hline \multirow{2}{*}{$\begin{array}{l}\text { Social: Social } \\
\text { bonds }\end{array}$} & Pearson Correlation &,- 042 &, $445^{* *}$ & 1 &,- 178 \\
\hline & $\mathrm{N}$ & 44 & 44 & 44 & 44 \\
\hline \multirow{3}{*}{$\begin{array}{l}\text { Structural: } \\
\text { Structural bonds }\end{array}$} & Pearson Correlation & 295 &,- 134 &,- 178 & 1 \\
\hline & Sig. (2-tailed) &, 050 &, 387 &, 247 & \\
\hline & $\mathrm{N}$ & 44 & 44 & 44 & 44 \\
\hline
\end{tabular}

**. Correlation is significant at the 0.01 level (2-tailed).

As shown in the results of Table 4, the degree of acceptance of the factor "social bonds" is generally slightly above the average of the scale (2.50).
As shown in the results of Table 5, the degree of acceptance of the initial factor "structural bonds" is generally high (2.50). The answers given by the companies, for each of 
the item, show an acceptance range of 3.18.

In order to correlate the factors "trust", "social bonds" and "structural bonds" and the benefits derived for the company from business to business relationships, a correlation test was performed between factor Benefits_1: Financial and the variables Reliance: Social: Social bonds and Structural: Structural bonds (Table 6).

It is observed that:

1. There is a statistically significant positive correlation of moderate intensity, between the variables Benefits_1: Financial and Reliance: Trust $(r=0.434 ; \mathrm{p}=0.003<0.05)$.

2. There is no statistically significant correlation between the variables Benefits 1: Financial and Social: Social bonds $(\mathrm{r}=-0.042 ; \mathrm{p}=0.786>0.05)$

3 . There is a statistically significant correlation between the low intensity variables between Benefits_1: Financial and Structural: Structural bonds $(\mathrm{r}=0.295 ; \mathrm{p}=0.0 \overline{5})$.

In particular, the better established the factors of trust and structural bonds, the higher the financial benefits that the company derives from its relationship with its partners.

From the above it can be seen that the hypotheses $\mathrm{H} 1$ and $\mathrm{H} 3$ are confirmed, while $\mathrm{H} 2$ is rejected.

\section{Conclusions}

In a highly competitive sector, managers tend to realize the importance of long-term partnerships and the benefits that come with them. The companies of the construction industry proceed to the development of associations, partnerships, joint ventures, multi-year cooperation agreements, joining forces not only for more efficient execution of the projects, but also for the joint confrontation of the market risks. The companies participated to the survey benefit from the development of long-term cooperation relations, especially in the financial terms, as it creates economies of scale, saves time and resources, pre-trades experience with partners and increases their competitive advantage. Through transactions, the processes are facilitated and the people of the cooperating companies communicate more directly and efficiently, processing easily the cases between them.

\section{Recommendations}

Research shows that companies trust their important partners, believe in their good intentions and that they are fair and honest with them. Having trust allows transactions to run smoothly, facilitates communication and reduces procedural delays.

However, there is some skepticism about the information they receive from their associates. Obviously, each company filters the information it receives from the environment and judges for itself whether it is important or not. However, the development of social bonds between employees of companies is not something that concerns cooperation between them. Research shows that developing friendships between employees is not very important for the transaction, nor is it particularly important if they agree or disagree on a personal level. In short, it does not bring any profit to the company whether the employees fit together as personalities or not.

On the contrary, the development of structural relations favors both involved parties. In long-term partnerships, each company makes concessions to the other, reducing costs, creating a special product to serve the partner and generally can carry out ad hoc procedures, which favor the other party. In a partnership that lasts over time, each side benefits from the special treatment it receives and research shows that companies in the construction industry recognize and value it.

The companies that took part in the research, belong to the construction sector, are located in Attica and are of medium and large size. Consequently, the results cannot be generalized, as there is the risk of not taking under consideration important information from other market segments. As a result, the conclusions drawn by the research are representative for construction companies of this size, but we do not know if they can be applied to smaller companies or companies located outside Attica or to other sectors of the economy.

However, we can say that despite any limitations or weaknesses, the present research provides stimuli and set the directions for further analysis and research.

It would be of great interest to enrich the sample with companies from other sectors, bearing different characteristics than the participated companies in the present research. It would be particularly interesting for a researcher to explore if there are other elements that shape long-term business relationships, beyond the three basic building bonds: trust, social and structural bonds.

\section{References}

[1] Ahmad, R., \& Buttle, F. (2001), "Customer retention: a potentially potent marketing management strategy", Journal of strategic marketing, Vol. 9, No. 1, pp. 29-45.

[2] Bendapudi, N., \& Berry, L. L. (1997), “Customers' motivations for maintaining relationships with service providers", Journal of retailing, Vol. 73, No. 1, pp. 15-37.

[3] Cross, R. and Smith, J. (1996), Customer Bonding: 5 Steps to Lasting Customer Loyalty. Lincolnwood: NTC Business Books.

[4] Dant, S. P., and Wilson, D. T. (1989), "Uncertainty Reduction: A Rationale for the Proliferation of InterOrganizational Relationships, in Proceedings: AMA Educators' Summer Conference, American Marketing Association, Chicago. 1989.

[5] Ganesan, S. (1994), "Determinants of long - term orientation in buyer - seller relationships", Journal of Marketing, Vol. 58, April, pp. 1-19.

[6] Geyskens, I. Steenkamp, J-B., Scheer, L. K., Kumar, N. (1998), "Generalization about Trust in Marketing Channel Relationships using Meta - Analysis", International Journal of Research in Marketing, Vol. 15, pp. 223-248. 
[7] Gounaris, S. P. (2005). Trust and commitment influences on customer retention: insights from business-to-business services. Journal of Business research, Vol. 58, No. 2, pp. 126-140.

[8] Gronroos, C. (1999), "Relationship Marketing: Challenges for the organizations", Journal of Business Research, Vol. 46, pp. 327-335.

[9] Han, S. L., Wilson, D. T., \& Dant, S. P. (1993), "Buyersupplier relationships today", Industrial marketing management, Vol. 22, No. 4, pp. 331-338.

[10] Hill C. and Jones T. (1992), "Stakeholders - Agency Theory", Journal of Management Studies, Vol. 22, pp. 131-154.

[11] Hillman A., Withers M. and Collins B. (2009), "Resource Dependence Theory: A Review", Journal of Management, Vol. 35, pp. 1404-1427.

[12] Hosmer, L. T. (1995), "Trust: The connecting link between organizational theory and philosophical ethics", Academy of management Review, Vol. 20, No. 2, pp. 379-403.

[13] Hütt, M. D., \& Speh, T. W. (1995), "Business Marketing Management: A strategic view of industrial and organizational markets", pp. 95-127.

[14] Johnson, D. and Grayson, K. (2005), "Cognitive and affective trust in service relationships", Journal of Business Research, Vol. 58, pp. 500-507.

[15] Lindgreen, A. and Crawford, I. (1999), "Implementing, monitoring and measuring a programme of relationship marketing", Marketing Intelligence and Planning, Vol. 17, No. 5, pp. 231-239.

[16] Luthardt, S. (2002), "In Suppliers versus Out Suppliers Determinants of Switching Behavior in Industrial Purchasing Relationships, in Proceedings of the 18th IMP-conference", Dijon France.

[17] Mayer, R. C., Davis, J. H. and Schoorman, F. D. (1995), “An Integrative Model of Organizational Trust", Academy of Management Review, Vol. 20, No. 3, pp. 709-734.

[18] McCutcheon, D. and Stuart, F. I. (2000), "Issues in the choice of supplier alliance partners", Journal of Operations Management, Vol. 18, pp. 279-301.

[19] Moorman, C., Deshpande, R. and Zaltman, G. (1993), "Factors Affecting Trust in Market Research Relationships", Journal of Marketing, Vol. 57 (January), pp. 81-101.

[20] Moorman, C., Zaltman, G. and Deshpande, R. (1992), "Relationships Between Providers and Users of Market Research: The Dynamics of Trust Within and Between Organizations", Journal of Marketing Research, Vol. 29 (August), pp. 314-329.

[21] Morgan, R. M. and Hunts, S. D. (1994), "The Commitment Trust Theory of Relationship Marketing", Journal of Marketing, Vol. 58 (July), pp. 20-38.

[22] Mudambi R. and Pedersen T., (2007), "Agency Theory and Resource Dependency Theory: Complementary Explanations for Subsidiary Power in Multinational Corporations", Center for Strategic Management and Globalization, Copenhagen Business School, Working Paper No 5/2007.

[23] Naude', P. and Buttle, F. (2002), “Assessing relationship quality", in Ford, D. (Ed.), Understanding Business Marketing and Purchasing, 3rd ed., Thomson Learning, London, pp. 34959.

[24] Nielson, C. C. (1998), "An Empirical Examination of the role of closeness in industrial buyer-seller relationships", European Journal of Marketing, Vol. 32, No. 5-6, pp. 441463.

[25] Perry, C., Cavaye, A., Coote, L. (2002), "Technical and Social Bonds With on Business to Business Relationships", Journal of Business and Industrial Marketing, Vol. 17, No. 1, pp. 7588 .

[26] Phan, M. C. T., Styles, C. W., \& Patterson, P. G. (1999, May), "An empirical examination of the trust development process linking firm and personal characteristics in an international setting", In Proceedings of the 28th European Marketing Academy Conference (EMAC), Vol. 1, p. 27.

[27] Rao, S. and Perry, C. (2002), "Thinking about relationship marketing: where are we now?", Journal of Business and Industrial Marketing, Vol. 17, No. 7, pp. 598-614

[28] Ring, P. S., \& Van de Ven, A. H. (1994), "Developmental processes of cooperative interorganizational relationships", Academy of management review, Vol. 19, No 1, pp. 90-118.

[29] Rodriquez, C. M., \& Wilson, D. T. (1999), "Relationship bonding and trust as foundation for commitment in international strategic alliances, USA-Mexico: A latent variable structural modeling approach”, ISBM Report, 21.

[30] Sako, M. (1992), "Prices, quality and trust: inter - firm relations in Britain and Japan", Cambridge University Press, Cambridge.

[31] Sarkar, M. B., Aulakh, P. S. and Cavusgil, S. T. (1998), "The strategic role of relational bonding in interorganizational collaborations: An empirical study of the global construction industry", Journal of International Management, Vol. 4, No. 2, pp. 85-107.

[32] Selnes, F. (1998), "Antecedents and consequences of trust and satisfaction in buyer-seller relationships", European Journal of marketing, Vol. 32 No. 3/4, pp. 305-322.

[33] Sheth, J. N., \& Parvatiyar, A. (1995), "The evolution of relationship marketing", International business review, Vol. 4, No. 4, pp. 397-418.

[34] Sin, Y. M., Leo, Tse C. B., Alan, Yau, H. M., Oliver, Chow, P M., Raymond, Lee, S. Y., Jenny, Lau, B. Y., Lau (2002), "Relationship marketing orientation: scale development and cross - cultural validation", Journal of Business Research, pp. $1-10$.

[35] Turnbull, P. W. and Wilson, D. T. (1989), "Developing and Protecting Profitable Customer Relationships", Industrial Marketing Management, Vol. 18, pp. 233-238.

[36] Walter, A., Hölzle, K., \& Ritter, T. (2002), "Relationship functions and customer trust as value creators in relationships: a conceptual model and empirical findings for the creation of customer value", In Proceedings of the Eighteenth IMPConference, Dijon, France.

[37] Wendelin, R. (2004), "The nature and change of bonds in industrial business relationships", Doctoral Dissertation No. 134, Swedish School of Economics and Business Administration, Helsinki. 
[38] Williams, J. D., Han, S. L., \& Qualls, W. J. (1998), “A conceptual model and study of cross-cultural business relationships", Journal of Business Research, Vol. 42, No. 2 , pp. 135-143.

[39] Wilson D. T., (1990), "Creating \& Managing Buyer -Seller Relationships", Research Report 5, Institute for the Study of Business Markets, Pennsylvania State University, University Park, PA.

[40] Wilson, D. T. (1995), "An Integrated Model of Buyer - Seller Relationships", Journal of the Academy of Marketing Science, Vol. 23, No. 4, pp. 335-345.
[41] Wilson, D. T. and Mummalaneni, V. (1986), "Bonding and commitment in buyer - seller relationships: a preliminary conceptualization", Industrial Marketing and Purchasing, Vol. 1, No. 3, pp. 44-58.

[42] Hillman, A. J., Withers, M. C., \& Collins, B. J. (2009), "Resource dependence theory: A review", Journal of management, Vol. 35, No 6, pp. 1404-1427.

[43] Zineldin, M. and Jonsson, P. (2000), "An examination of the main factors affecting trust/commitment in supplier - dealer relationships: an empirical study of the Swedish wood industry", The TQM Magazine, Vol. 12, No. 4, pp. 245-265. 